\title{
EL AUTOR Y SU PROTECCIÓN CONSTITUCIONAL EN EL URUGUAY CONSIDERACIONES GENERALES
}

\author{
Beatriz Bugallo Montaño ${ }^{1}$
}

\section{RESUMEN}

En la Constitución uruguaya vigente, de 1967 se consagra expresamente la protección del autor en el artículo 33. Se sigue, de esta forma, una tendencia difundida en el Derecho Comparado. En particular, se lo hace desde la perspectiva de su valoración como trabajo intelectual. La consagración constitucional implica analizar el contexto normativo constitucional, así como la dimensión programática de la norma. Esta opción del constitucionalista refuerza la consideración de la protección del autor en el Derecho uruguayo. Uruguay

Palabras-clave: Autor. Constitución. Derechos Humanos. Trabajo.

\section{INTRODUCCIÓN}

En la práctica totalidad de los sistemas jurídicos nacionales del mundo se encuentra consagrado y regulado el derecho de autor, sin lugar a dudas, en un plano legal.

En muchos países también se encuentra consagrado en la respectiva Constitución, ya sea expresamente (en muchísimas ocasiones) como de manera explícita en las libertades y garantías consagradas.

En este trabajo planteamos la forma en la cual se encuentra prevista la tutela constitucional del derecho de autor en el Derecho uruguayo, los efectos de tal previsión y la proyección que implica a todo el ordenamiento jurídico nacional.

\section{LOS DERECHOS CONSAGRADOS EN LA CONSTITUCIÓN}

Los derechos humanos, su defensa y consagración normativa constitucional, aparecen como una forma de limitación al poder político. Ello constituye uno de los efectos directos del Estado de Derecho, particularmente cuando pasa a calificarse como un Estado Liberal de Derecho, trascendiendo también a las aproximaciones constitucionales contempóraneas, en los casos de consideración de Estado social.

Progresivamente se ha ido consagrando derechos y garantías, en un principio aquéllos de dimensiones básicas, seguidos luego por los derechos del ámbito socio-económico y cultural, categorizados como derechos civiles.

REVISTA DO DIREITO UNISC, SANTA CRUZ DO SUL NN 35|P. 71-83| JAN-JUN 2011 
La inclusión de derechos, calificados como fundamentales - sea por la doctrina y jurisprudencia, como por el propio Derecho Internacional - genera una obvia consideración sobre sus efectos. Es decir, corresponde formular las razones y el significado de la inclusión de derechos de rango constitucional. Suele afirmarse que la selección de derechos con dicho rango que ha realizado el legislador constitucional contemporáneo, implica considerar los mismos como esenciales o relevantes para el funcionamiento del sistema jurídico que la Constitución que se trata pretenden sustentar.

De manera que como categoría jurídica, como derechos, resultan indisponibles para el legislador, quien - naturalmente y siguiendo también los preceptos constitucionales - podrá reglamentar, limitar sobre la base del interés general o sobre la base de la búsqueda de equilibrio con otros derechos de igual rango. Se garantiza así el ejercicio básico para los ciudadanos.

Si bien es cierto que se ha distinguido diverso rango entre todos los derechos consagrados constitucionalmente, incluso se habla de una mayor 0 menor "fundamentalidad" entre todos. De todas formas, la protección y rango especiales resulta formalmente atribuida.

\section{DERECHO DEL AUTOR Y CONSTITUCIÓN}

En varias constituciones de países iberoamericanos se incluye un precepto que consagra el derecho de autor, ya sea con tal expresión, ya sea incluido en el concepto más moderno y general de propiedad intelectual.

En el caso de la Constitución española, por el contrario, en la que no se encuentra expresamente contemplado la doctrina constitucionalista ha elaborado a partir de las libertades y garantías consagradas, la fundamentación que lo justifica y garantiza. vigentes:

A modo de ejemplo, enunciamos los siguientes casos de constituciones

a) Argentina, artículo 17, "La propiedad es inviolable, y ningún habitante de la Nación puede ser privado de ella, sino en virtud de sentencia fundada en ley. La expropiación por causa de utilidad pública, debe ser calificada por ley y previamente indemnizada. Sólo el Congreso impone las contribuciones que se expresan en el artículo 4o. Ningún servicio personal es exigible, sino en virtud de ley o de sentencia fundada en ley. Todo autor o inventor es propietario exclusivo de su obra, invento o descubrimiento, por el término que le acuerde la ley. La confiscación de bienes queda borrada para siempre del Código Penal argentino. Ningún cuerpo armado puede hacer requisiciones, ni exigir auxilios de ninguna especie.";

b) Brasil, artículo 5, "XXVII - aos autores pertence o direito exclusivo de REVISTA DO DIREITO UNISC, SANTA CRUZ DO SUL № 35|P. 71-83| JAN-JUN 2011 
utilização, publicação ou reprodução de suas obras, transmissível aos herdeiros pelo tempo que a lei fixar;"; ello sin perjuicio de la dimensión de función social que según preceptos generales alcanza también al ejercicio de esta titularidad de derechos;

c) Colombia, artículo 61, "El Estado protegerá la propiedad intelectual por el tiempo y mediante las formalidades que establezca la ley";

d) Chile, artículo 19, "La Constitución asegura a todas las personas:" (...) " $25^{\circ}$ La libertad de crear y difundir las artes, así como el derecho del autor sobre sus creaciones intelectuales y artísticas de cualquier especie, por el tiempo que señale la ley y que no será inferior al de la vida del titular.

El derecho de autor comprende la propiedad de las obras y otros derechos, como la paternidad, la edición y la integridad de la obra, todo ello en conformidad a la ley.

Se garantiza, también, la propiedad industrial sobre las patentes de invención, marcas comerciales, modelos, procesos tecnológicos u otras creaciones análogas, por el tiempo que establezca la ley.";

e) Ecuador, artículo 22, "Las personas tienen derecho a desarrollar su capacidad creativa, al ejercicio digno y sostenido de las actividades culturales y artísticas, y a beneficiarse de la protección de los derechos morales y patrimoniales que les correspondan por las producciones científicas, literarias 0 artísticas de su autoría.";

f) Mexico, artículo 28: "(...) Tampoco constituyen monopolios los privilegios que por determinado tiempo se concedan a los autores y artistas para la producción de sus obras y los que para el uso exclusivo de sus inventos, se otorguen a los inventores y perfeccionadores de alguna mejora. $(\ldots)^{\prime \prime}$;

g) Paraguay, artículo 110, "Todo autor, inventor, productor o comerciante gozará de la propiedad exclusiva de su obra, invención, marca o nombre comercial, con arreglo a la ley.";

h) Venezuela, artículo 98, "La creación cultural es libre. Esta libertad comprende el derecho a la inversión, producción y divulgación de la obra creativa, científica, tecnológica y humanística, incluyendo la protección legal de los derechos del autor o de la autora sobre sus obras. El Estado reconocerá y protegerá la propiedad intelectual sobre las obras científicas, literarias y artísticas, invenciones, innovaciones, denominaciones, patentes, marcas y lemas de acuerdo con las condiciones y excepciones que establezcan la ley y los tratados internacionales suscritos y ratificados por la República en esta materia.". 


\section{CONSTITUCIÓN URUGUAYA Y DERECHO DE AUTOR}

\subsection{Disposición que lo consagra}

La protección constitucional del derecho de autor en el Uruguay comienza con la inserción en la Constitución de 1934 de una norma que lo consagra como un derecho básico. Sigue así la tendencia internacional de los años posteriores a la Primera Guerra Mundial, que incorpora como derechos fundamentales temáticas de diversa naturales ${ }^{2}$.

La norma dice así:

"Artículo $33^{\circ}$. El trabajo intelectual, el derecho del autor, del inventor o del artista, serán reconocidos y protegidos por la ley."

La protección legal del Derecho de Autor en Uruguay es bastante anterior a su consagración constitucional ${ }^{3}$, pues estaba incluida - aunque de manera genérica - en una disposición del Código Civil de la República Oriental del Uruguay vigente desde 1869.

Es de recordar, de épocas anteriores al referido Código Civil (actualmente vigente en sus disposiciones estructurales, aunque ha sufrido muchas modificaciones y actualizaciones), que durante la época colonial, rigió la regulación de la potencia dominante para sus colonias, que, en materia de derecho de autor, incluyó la concesión de privilegios para la impresión de algunas obras, reflejo de la situación europea ${ }^{4}$. Luego de la independencia de nuestro país se reguló en materia de libertad de expresión y libertad de prensa, a través de leyes de imprenta, pero tampoco se tuvo en consideración derechos para el autor de las creaciones intelectuales ${ }^{5}$.

La primera ley nacional que reguló los derechos de autor fue promulgada el 15 de marzo de 1912, ley № 3.956. Mediante esa ley el legislador uruguayo cumplió la disposición del Código Civil que le determinaba la elaboración de legislación especial y, además, se puso a tono con el derecho comparado que en los distintos Estados, desde el siglo XVIII había tratado la temática en una ley específica.

Constaba de treinta y cuatro artículos y fue de fundamental importancia en su momento: reguló los derechos de creadores, su duración, el registro de las obras y su alcance. Además, incluyó disposiciones sobre reproducción ilícita (enunciando actos donde la hay y donde no la hay) a manera de la forma que actualmente tenemos incluida en la legislación vigente.

Con el tiempo se consideró que esta ley tenía dos defectos, adoleciendo "del vicio de dejar en absoluto desamparo al autor extranjero y de defender mal al nacional, frente a los indiscutibles progresos de la técnica" ${ }^{6}$. Tal lo que expresara el Mensaje del Poder Ejecutivo a la Asamblea General en el año de 1937 cuando impulsó una reforma que, a través de diversas iniciativas se venía 
persiguiendo desde más de diez años antes.

De todas maneras, es en 1934 - cuando se incorporan toda una serie de derechos, deberes y garantías, modernizándose el Derecho Constitucional uruguayo -, que la protección del autor y sus derechos puede decirse tutelada específicamente con rango constitucional.

Del texto planteado podemos distinguir los siguientes elementos:

a) el objeto de protección, "trabajo intelectual, el derecho del autor, del inventor, del artista";

b) sujetos protegidos, "autor, inventor, artista";

c) mandato constitucional, "serán reconocidos y protegidos por la ley".

\subsubsection{Objeto de protección}

En la enunciación específica del objeto de protección encontramos una particularidad de la norma constitucional uruguaya: se hace referencia, en primer lugar, al trabajo como destinatario de dicha protección constitucional.

Está claro que el legislador constitucional hizo referencia a la creación intelectual como fruto de la creación humana. Es decir, sin incluir en la protección ningún tipo de hallazgo a adquisición que no implique intervención humana, capacidad intelectual de aplicar energía a la producción de una creación.

Veremos que, tomando como núcleo al trabajo, la tutela de la creación intelectual se potencia también a través de las normas tuitivas generales del trabajo.

\subsubsection{Sujetos protegidos}

Desde una perspectiva amplia, los sujetos cuyo trabajo intelectual es protegido se encuentran diversificados según se trata de autor, inventor o artista. Es decir, quedan comprendidos los creadores, propiamente, del mundo de la propiedad intelectual.

Es lógico que, de las creaciones de la propiedad intelectual, las marcas y sus titulares resulten excluidos de esta disposición en particular: los signos distintivos se encuentran directamente vinculados con las libertades económicas de marco constitucional.

\subsubsection{Mandato constitucional}

El mandato constitucional al marco legal se puede dividir en dos partes. 
En primer lugar, se establece que los derechos deberán ser "reconocidos". Es decir, que se espera que se enuncie y defina el marco de reconocimiento de los derechos protegidos. El reconocimiento admite también establecer requisitos.

En segundo lugar, la norma que analizamos establece que el trabajo o los derechos serán "protegidos". Es una forma de imponer que se reglamente también el ejercicio de las correspondientes acciones y mecanismos que permitan la defensa de los titulares frente a cualquier tipo de vulneración.

La regulación de todos estos aspectos debe seguir también las obligaciones internacionales contraidas por el Uruguay en diversos tratados. De manera que, si bien la Constitución es amplia al referirse a reconocimiento y protección, no plantea más pautas que lo que puede implicar no contradecir el juego de diversos derechos consagrados por la propia Constitución, la facultad del legislador no es totalmente independiente, ni puede ser arbitraria.

De la consagración de esta disposición se derivan dos planos de consideraciones:

a. que el derecho del autor tiene un plano de protección constitucional;

b. que se trata de una norma programática.

\subsection{Derecho de autor en Uruguay: como derecho de nivel constitucional}

En Uruguay la jerarquía constitucional de la protección de un derecho implica la consagración del mismo como valor, con especial atención por parte del legislador constitucional.

No se trata de ningún tipo de exigencia particular en cuanto a forma de legislación, ni especial competencia en materia de decisión jurisdiccional. En Uruguay carecemos de este tipo de organización formal.

No obstante, la seguridad del reconocimiento constitucional, desde el punto de vista sustancial, es indudable.

\subsection{Carácter programático del artículo 33 de la Constitución uruguaya}

La norma analizada, indudablemente programática en cuanto a su detallada regulación, ha planteado en más de un caso la duda respecto de si por sí implica también un reconocimiento del derecho o si éste mismo queda circunscripto a la norma legal. 
Siguiendo la tendencia mayoritaria, se considera que la - lógica circunstancia de que no tenga expresa consagración constitucional no puede implicar el desconocimiento de tal máximo nivel de protección. Si tal no hubiera sido la intención del legislador, directamente no debería haberse incluido en als modificaciones de 1934, habiendo permanecido dicha materia regulada exclusivamente en la ley tal como lo estaba desde 1912.

La respuesta del legislador a la norma constitucional que impone reconocimiento y protección legales, tuvo lugar pocos años después de 1934. Se trata de la ley sobre protección literaria, artística y científica № 9.739 actualmente vigente, con toda una serie de modificaciones y actualizaciones, que se aplica en consonancia con la variada serie de de tratados, convenciones y convenios internacionales de los que el Uruguay es Estado parte.

En la redacción del proyecto que fuera más tarde la ley № 9.739 de 17 de diciembre de 1937, es innegable la participación y el impulso del entonces Ministro Eduardo Víctor Haedo ${ }^{7}$. No obstante, corresponde destacar como lo hace el propio Mensaje del Poder Ejecutivo a Italo Perotti / Lorenzo Vicens Thuevent y Mario Dupont Aguiar, autores de proyectos legislativos anteriores, así como a Angel Cusano, legislador que trabajó intensamente en el tema ${ }^{8}$.

La ley de 1937 fue un magnífico ejemplo normativo, elogiado desde el exterior $^{9}$ y que - a pesar de ser tratada a último momento de un año legislativo, levantando el receso al efecto ${ }^{10}$ - fue considerada satisfactoria en el ámbito nacional.

Es, prácticamente, la ley que tenemos, con las modificaciones introducidas por la reforma de la ley № 17.616 de 10 de enero de 2003, con el principal objetivo de ajustar nuestra legislación a las obligaciones internacionales contraídas por el Uruguay en el Acuerdo sobre los Aspectos de los Derechos de Propiedad Intelectual relacionados con el Comercio, por ser miembro de la Organización Mundial de Comercio y alguna otra actualización ${ }^{11}$.

Lamentablemente los proyectos más estructurados que fueron presentados desde la década de los ochenta del siglo XX hasta la reforma promulgada en el año 2003 no prosperaron por falta de voluntad política. Constituyeron iniciativas que proponían verdaderos Códigos para la regulación de los derechos de autor y conexos, modernos, ajustados a los requerimientos actuales, también con preceptos polémicos, pero con una visión global muy definida $^{12}$.

\subsection{Contexto constitucional del artículo 33 de la Constitución uruguaya}

La protección constitucional que otorga la norma del artículo 33 de la REVISTA DO DIREITO UNISC, SANTA CRUZ DO SUL № 35|P. 71-83| JAN-JUN 2011 
Constitución uruguaya al Derecho de Autor, debe analizarse en el contexto constitucional nacional, de lo que deriva que existe una múltiple regulación constitucional como enseña el Prof. Gros Espiell ${ }^{13}$.

Por ello, habremos de mencionar las principales normas constitucionales que resultan fundamentales para analizar la jerarquía constitucional de los derechos del artículo 33.

\title{
3.4.1 En cuanto al fundamento de las limitaciones que se legislaran
}

\begin{abstract}
"Artículo $7^{\circ}$. Los habitantes de la República tienen derecho a ser protegidos en el goce de su vida, honor, libertad, seguridad, trabajo y propiedad. Nadie puede ser privado de estos derechos sino conforme a las leyes que se establecieron por razones de interés general."
\end{abstract}

De manera que para toda situación que implique limitar el derecho del autor, sea en sí mismo, sea en relación con otros derechos con los que se encuentre en tensión, el fundamento al que debe apelar el legislador para que sea admisible la disposición es el "interés general".

\subsubsection{Conjugado con la protección general de la libertad de trabajo}

\author{
"Artículo $36^{\circ}$. Toda persona puede dedicarse al trabajo, cultivo, \\ industria, comercio, profesión o cualquier otra actividad lícita, salvo \\ las limitaciones de interés general que establezcan las leyes."
}

El trabajo tiene distinta reglamentación. Puede tratarse del trabajo del comerciante, que se regula por el Derecho Comercial; el trabajo del agricultor, con sus normas específicas de Derecho Agrario; del trabajo en relación de dependencia, con sus disposiciones del Derecho del Trabajo o Derecho Laboral. Y así sucesivamente con las distintas actividades y sus respectivas regulaciones.

Especifica esta norma, - como la anterior, más general, establecida para todos los derechos - que deberá justificarse en el interés general cualquier limitación a la libertad consagrada.

\section{particular \\ 3.4.3 Conjugado con la protección al trabajo en perspectiva} "Artículo $53^{\circ}$.El trabajo está bajo la protección especial de la ley.
Todo habitante de la República, sin perjuicio de su libertad, tiene el
deber de aplicar sus energías intelectuales o corporales en forma que
redunde en beneficio de la colectividad, la que procurará ofrecer, con
preferencia a los ciudadanos, la posibilidad de ganar su sustento
mediante el desarrollo de una actividad económica."

En este caso, también por la referencia a "trabajo intelectual" del artículo 
33, resulta amparada la actividad económica que realice el autor o artista.

El trabajo del creador intelectual puede ser tanto por su propia iniciativa como en relación de dependencia. En cualquier caso será amparado, por el principio tuitivo dispuesto por la Constitución.

\title{
3.4.4 Como competencia legislativa de la Asamblea General
}

\author{
"Artículo $85^{\circ}$. A la Asamblea General compete:" (...) \\ “3\%) Expedir leyes relativas a la independencia, seguridad, \\ tranquilidad y decoro de la República; protección de todos los \\ derechos individuales y fomento de la ilustración, agricultura, \\ industria, comercio interior y exterior."
}

En cuanto temática general, resulta incluida dentro de la competencia general de la Asamblea General, lo cual no implica un procedimiento legislativo específico.

\subsubsection{Sobre la aplicación}

\begin{abstract}
"Artículo $332^{\circ}$. Los preceptos de la presente Constitución que reconocen derechos a los individuos, así como los que atribuyen facultades e imponen deberes a las autoridades públicas, no dejarán de aplicarse por falta de la reglamentación respectiva, sino que ésta será suplida, recurriendo a los fundamentos de leyes análogas, a los principios generales de derecho y a las doctrinas generalmente admitidas."
\end{abstract}

Desde el momento en que entendemos que la protección del trabajo intelectual se encuentra expresamente reconocido por la Constitución (su carácter programático lo es en cuanto la regulación de aplicación, no en cuanto su existencia) es de aplicación esta norma.

Si bien no tuvo nunca aplicación específica para el derecho de autor, dado que su regulación legal es anterior a su categorización constitucional, lo deja al amparo de cualquier ausencia de regulación normativa.

\subsection{Respaldo internacional de la consagración como derecho fundamental de rango constitucional}

A nivel del Derecho Internacional la primera regulación del derecho de autor se introduce con la ratificación del Tratado de Montevideo de 1889, mediante la ley № 2.207 de 1ํㅡㄹ de octubre de 1892, y luego de la Convención de Buenos Aires de 1910, mediante la ley № 6.103 de julio de 1918.

Actualmente podemos citar tres Tratados internacionales en los que se REVISTA DO DIREITO UNISC, SANTA CRUZ DO SUL No 35|P. 71-83| JAN-JUN 2011 
encuentra incorporado nuestro país. Los enumeramos a continuación.

Pacto Internacional de Derechos Económicos, Sociales y culturales de las Naciones Unidas, 1966, artículo 15, 1 c, según la cual se reconoce el derecho de toda persona a "beneficiarse de la protección de los intereses morales y materiales que le correspondan por razón de las producciones científicas, literarias o artísticas de que sea autora".

Declaración Americana de Derechos y Deberes del Hombre, aprobada en Bogotá, abril de 1948, artículo XIII, inciso 2, que proclamara el derecho de toda persona a "la protección de los intereses morales y materiales que le correspondan por razón de los inventos, obras literarias y artísticas de que sea autor".

Declaración Universal de Derechos Humanos, del 10 de diciembre de 1948, artículo 27 párrafo 2, haciendo referencia a: "el derecho a la protección de los intereses morales y materiales que toda persona tiene por razón de las producciones científicas, literarias o artísticas de que sea autor"

Estos documentos internacionales son todos ellos de ratificación posterior a la inclusión de tales derechos en la Constitución uruguaya. De todas maneras, sustentan con un rango particular, de obligaciones internacionales del Estado uruguayo, la protección del derecho de autor, reforzándolo de dicha manera.

Por supuesto que los mencionados Tratados son generales, queríamos destacar la inclusión del derecho del autor en la correspondientes enunciaciones. Sin perjuicio de ello, hemos de destacar el valor indudable de la variada normativa internacional específica a la materia, que respalda rotundamente la protección legal de los creadores intelectuales.

\section{CONCLUSIÓN}

En definitiva, podemos expresar que la protección constitucional del derecho de autor contenida en la Constitución actualmente vigente en Uruguay tiene larga data.

Jerarquiza a este derecho, dentro del elenco de todos, a través de una consideración en múltiples artículos, destacándole en su faceta de creación derivada del trabajo. Sigue de esta forma una tendencia definida de Derecho Comparado, tuitiva y defensora del autor y sus derechos, reflejada como valor en distintas leyes nacionales.

Merece actualmente una nueva lectura, dimensionada a un rol social, que las innovaciones legislativas en discusión habrán de modelar adecuadamente.

THE AUTHOR AND HIS CONSTITUTIONAL PROTECTION IN THE

REVISTA DO DIREITO UNISC, SANTA CRUZ DO SUL NN 35|P. 71-83| JAN-JUN 2011 


\title{
URUGUAY GENERAL CONSIDERATIONS
}

\begin{abstract}
Current Uruguayan Constitution of 1967 explicitly enshrines the protection of copyright in section 33. Follosw, thus, a widespread tendency in comparative law. In particular, it is done from the perspective of its value as work, as intellectual one. The Constitution text drives us to analyze constitutional legislative context and the ulterior regulation of policy dimension of the standard. The system reinforces the consideration of constitutional protection of copyright in the Uruguayan law.
\end{abstract}

Key-Words: Author. Constitution. Human Rights. Labor. Uruguay.

\section{A PROTEÇÃO CONSTITUCIONAL DO AUTOR NO URUGUAI GERALIDADES}

\section{RESUMO}

Constituição uruguaia actual, de 1967, consagra expressamente a proteção dos direitos de autor no artigo 33. Segue uma tendência generalizada no direito comparado. Em particular, é feito a partir da perspectiva de seu valor como trabalho intelectual. A Constituição nos determina para analisar o contexto constitucional e a dimensão da ulterior regulaçao legal da norma. Esta opção reforça a proteção constitucional do direito de autor no direito uruguaio.

Palavras-chave: Constituição. Direito Do Autor. Direitos Humanos. Trabalho. Uruguai.

\section{NOTAS}

1. Abogada (UDELAR, Uruguay), Master en Propiedad Intelectual y Nuevas Tecnologías (UA. España) Doctora en Derecho (USC, España), Profesora de Derecho Comercial y Propiedad Intelectual (Universidad de Montevideo, UDELAR, Uruguay).

2. Vé BISCARETTI DI RUFFIA, "Derecho Constitucional", pág. 668 y ss.

3. La primera disposición legal referida al derecho de autor se encuentra en el artículo 443 del Código Civil: "Las producciones del talento o del ingenio son una propiedad de su autor y se regirán por leyes especiales".

4. GROMPONE, "EI derecho de autor en Uruguay", pág. 22, explica la situación de vacío respecto de la materia autoral en el derecho indiano. Por su parte, VALDÉS OTERO, pág. 27 y ss. presenta un estudio más detallado desde la perspectiva de la Historia del Derecho.

5. GROMPONE, "El derecho de autor en Uruguay", pág. 23.

6. Cámara de Representantes, № 9422 15/12/1937, pág. 182.

7. Eso indica GROMPONE, "El derecho de autor en el Uruguay", pág. 27. 
8. Cámara de Representantes, cit.

9. RADAELLI/MOUCHET, "La nueva ley uruguaya", en 36 RDJA 1938, pág 253, dijeron que se trataba de "una contribución de importancia en la legislación sobre la materia".

10. También la última reforma, de 2003 , fue aprobada <de apuro>, levantando el receso de diciembre de 2002. Lamentablemente esta reforma en el apuro dejó sin corroborar algunos efectos de la reforma y varios temas pendientes de actualización.

11. En el Informe de la Comisión de Educación y Cultura de la Cámara de Representantes al Plenario, luego de estudiado el proyecto se establece "En tal sentido puede entenderse como un poryecto mínimo que intenta innovar sólo lo imprescindible.", Carpeta № 2254 de 2002, Anexo I al Repartido № 1005.

12. Las iniciativas comienzan con un proyecto de ley de Derechos de Autor y Afines enviado por el Poder Ejecutivo al Parlamento con fecha 21 de marzo de 1988. En el Mensaje correspondiente explicaba que en la iniciativa "no sólo se refleja el acuerdo de todos los sectores directamente involucrados, sino además el respaldo de la más especializada organización internacional en la materia", Se había enviado un experto internacional de la OMPI para su formulación. El proyecto fue luego revisado en los años 1994 y 1995, por el especialista internacional Antequera Parilli. No fue aprobado. Posteriormente, el 28 de mayo de 1997 el Poder Ejecutivo envía al Parlamento otro Proyecto de Ley sobre Derecho de Autor y Derechos Afines, que tampoco tuvo éxito.

Como los textos anteriores eran muy extensos y habían dado lugar a diversos debates, se optó por no pretender una actualización integral del derecho de autor nacional. De modo que, siguiendo esta tesitura se envió al Parlamento otro Proyecto de ley el 19 de mayo de 2000.

Estando en consideración en la Comisión de Educación y Cultura de la Cámara de Representantes se recomendó al Plenario desglosar de las normas del último proyecto las correspondientes al software para propiciar una consideración más urgente, mientras se discutía los demás aspectos. El desglose o separación se llevó a cabo efectivamente, haciendo sido - curiosamente - merecedores de media sanción. Dichos proyectos no cumplieron totalmente el íter de aprobación legislativa.

Por último, el Poder Ejecutivo decidió realizar solamente aquellos ajusten absolutamente necesarios para superar inconsistencias de la ley de 1937, cumplir con las obligaciones internacionales fundamentales, pero sin realizar cambios estructurales en la legislación vigente hasta el momento. Esta iniciativa es la que en definitiva prosperó y constituye la reforma del 2003 introducida por la ley № 17.616.

13. GROS ESPIELL, "El trabajo intelectual", pág. 11.

\section{BIBLIOGRAFÍA}

BISCARETTI DI RUFFIA, Paolo, "Derecho Constitucional", trad. Pablo Lucas Verdú, Madrid: Tecnos, 1ra edición, reimpresión, 1973.

BUGALLO, Beatriz, “Propiedad Intelectual”, Montevideo: FCU, 2006.

DE FREITAS, Eduardo, BORGGIO, Plinio, "Temas de derecho autoral", Montevideo, 1993.

GELSI BIDART, Adolfo, "De derechos, deberes y garantías del hombre común", Montevideo: BdF, 2006.

GROMPONE, Romeo, "El Derecho de Autor en Uruguay", Montevideo: 1977GROMPONE, Romeo, "El Derecho de Autor en Uruguay", Montevideo: 1977

REVISTA DO DIREITO UNISC, SANTA CRUZ DO SUL NN 35|P. 71-83| JAN-JUN 2011 
GROS ESPIELL, Héctor, "El trabajo intelectual. Constitución, ley y derecho internacional", Montevideo, AGADU, 1999, 18 pág.

, "Los Derechos Culturales en cuanto Derechos Humanos en el Derecho Internacional", en "Revista Uruguaya de Derecho Constitucional y Político", tomo XI, No 62 .

RADAELLI/MOUCHET, "La nueva ley uruguaya de propiedad literaria y artística", en 36 Revista de Derecho, Jurisprudencia y Administración, 1938 RISSO FERRAND, Martín, "Derecho Constitucional", tomo I, Montevideo: FCU, 2006.

VALDES OTERO, Estanislao, "Derecho de autor", Montevideo: Facultad de Derecho de la Universidad de la República, 1953.

Recebido para publicação: 11/11/2011

Aceito ara publicação: 13/12/2011 